
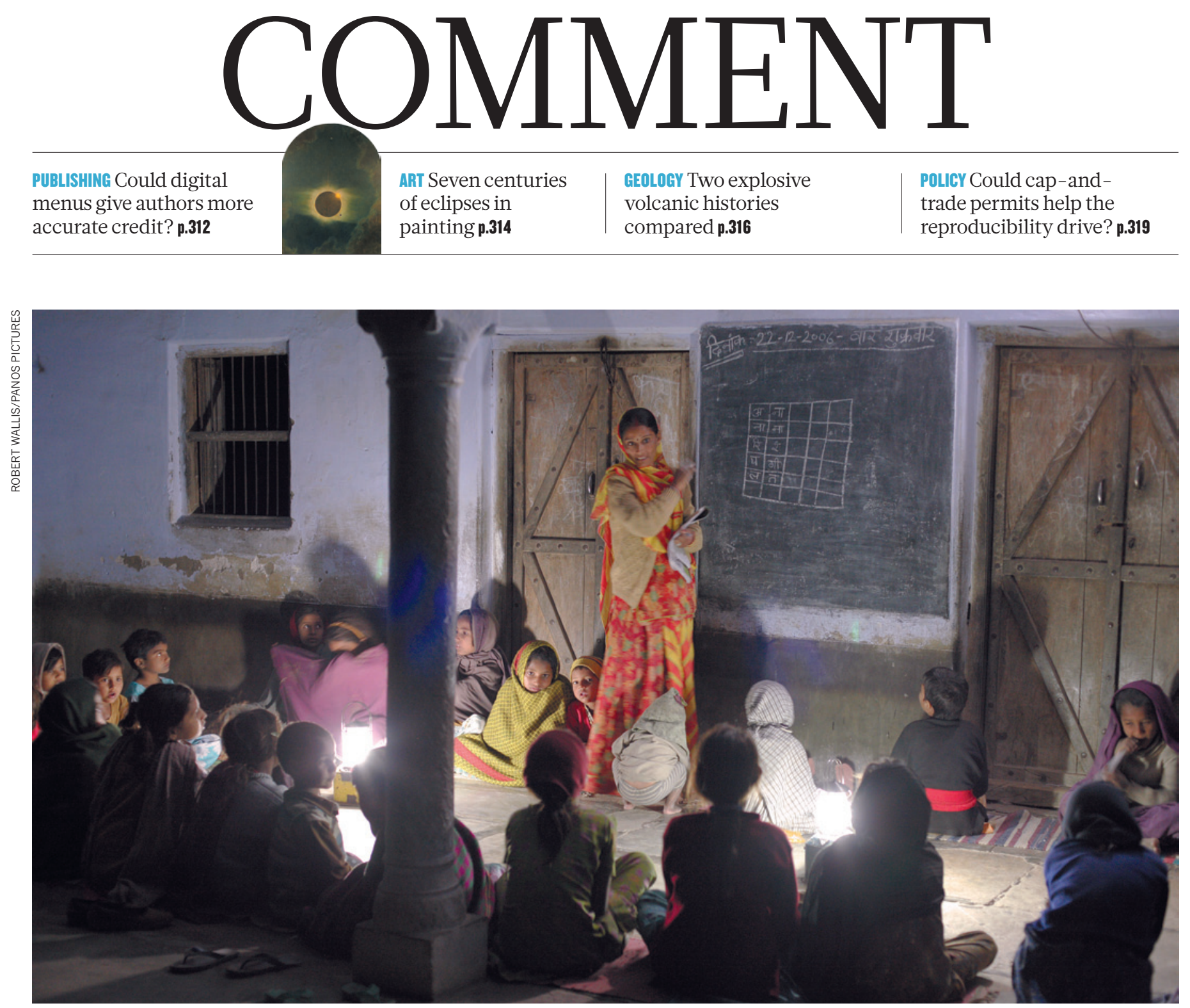

Solar lanterns light up evening schools in India.

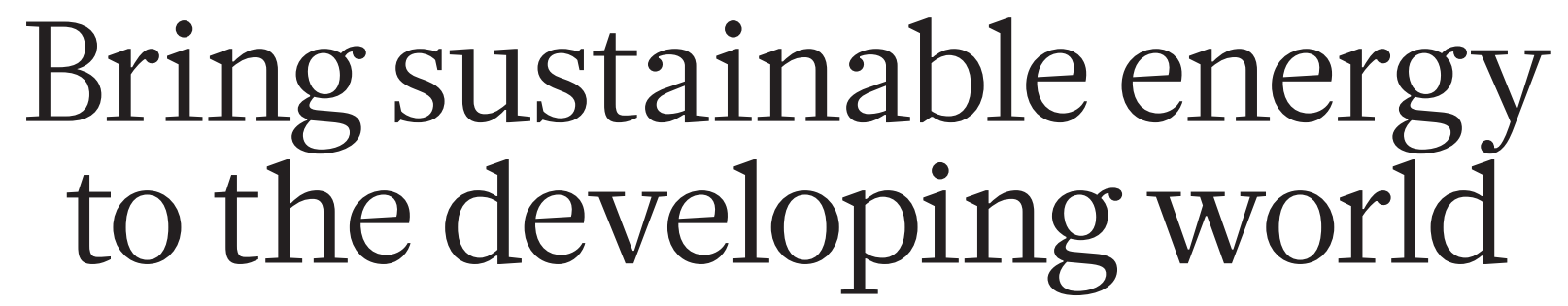

Investment and policies must support cheap, clean energy technologies to cut both poverty and climate change, say Reid Detchon and Richenda Van Leeuwen.

$\mathrm{M}$

ore than one-third of people in the world start life without access to electricity and clean fuels for cooking, heating and lighting ${ }^{1}$. United Nations secretary-general Ban Ki-moon was one of them, studying at night by a dim, smoky oil lamp as a boy in 1950s post-war Korea. He now sees energy as "the golden thread that connects economic growth, social equity, and environmental sustainability".
In 2011, Ban launched the UN initiative Sustainable Energy for All. It sets out three objectives for 2030: universal access to modern energy services; doubling the global rate of improvement in energy efficiency; and doubling the share of renewables in the global energy mix.

The initiative gained traction quickly among member states and international and regional banks because it combines global emissions-reduction and development goals. Clean energy will improve the lives of the world's poor and is crucial to keeping the rise in average global temperatures to within $2^{\circ} \mathrm{C}$ of pre-industrial levels - the goal agreed by the UN Framework Convention on Climate Change in 2010.

Yet the pace of progress towards clean energy for all has failed to match the urgency of addressing climate change 
and global poverty. Renewable energy has become economically competitive with conventional fuels only in about the past five years, and reaching dispersed rural populations poses logistical challenges. If policies remain unchanged, the UN objectives will not be met.

Market-led approaches are suited to rolling out clean-energy technologies across the developing world, if affordable financing is made available and supported by local and national policies. To achieve universal energy access, investment capital must be matched to a pipeline of viable energy projects and enterprises.

\section{ENERGY POVERTY}

Nearly 1.3 billion people, mostly in Africa and south Asia, lack access to electricity and the development benefits it can provide to improve health, education and economic opportunity. Almost as many people have power only intermittently. And around 2.6 billion people use solid fuels - mostly biomass, dung and coal for cooking and heating, including onethird of the population of China ${ }^{1}$.

The International Energy Agency (IEA) estimates $^{1}$ that almost 1 billion people will still be without access to electricity in 2030, in part owing to rapid population growth, mostly in sub-Saharan Africa and south Asia (see 'Power up'). The number of people without access to clean cooking stoves and fuels is similarly projected to drop only slightly, from 2.6 billion to 2.5 billion.

Energy inequality falls most heavily on rural women and girls, who may spend many hours a week collecting firewood far from home, risking their personal safety. Inhaling smoke from conventional cooking fires and kerosene lamps causes respiratory disease, heart disease and burns, and led to 4.3 million premature deaths ${ }^{2}$ globally in 2012 - more than malaria, tuberculosis and HIV/AIDS combined.

Access to modern energy also affects the delivery of health services. In a 2013 review $^{3}$ of 4,640 medical facilities in 11 countries in

"Where
financing
opportunities
exist, anew
breed of
clean-energy
entrepreneurs
is emerging."
sub-Saharan Africa, $26 \%$ had no electricity. Doctors and midwives delivering babies use whatever poor-quality lighting is available - kerosene lanterns, candles and even mobile phones - or make do in the dark. Newborns can be scarred by dripping candle wax. Mothers die from treatable conditions.

Even small interventions can save lives. When Laura Stachel, an obstetrician in California, travelled to northern Nigeria in 2008, her torch helped local doctors to finish an emergency Caesarean section when the power went out. Back home, she and her husband developed a portable solar electric system - a 'solar suitcase' - to provide power for lighting, laptops, phones and small medical devices The systems cost about US $\$ 5,000$, including transport, installation and training. Hundreds are now used in clinics in 30 countries and have cut maternal deaths by as much as $70 \%$ in some cases.

Expanding electricity grids - the main

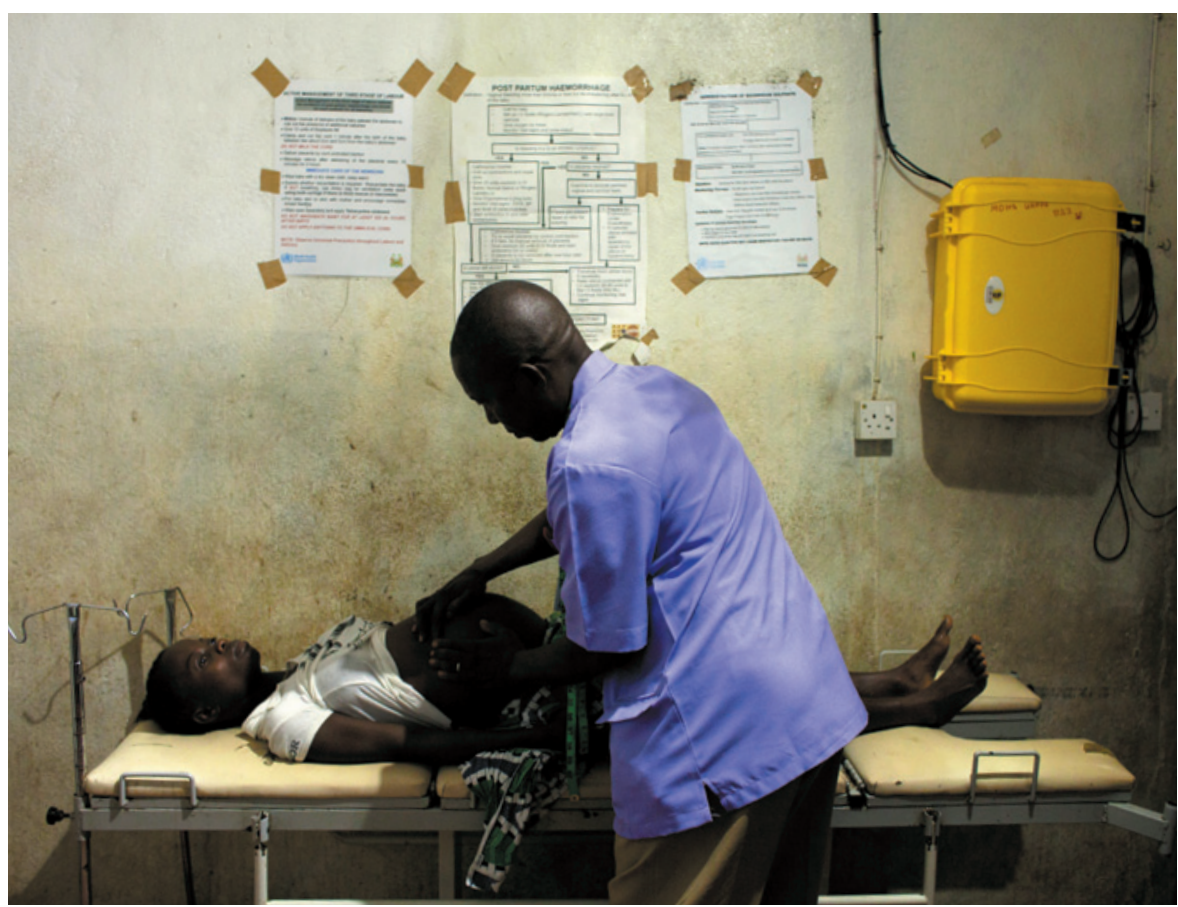

A wall-mounted 'solar suitcase' delivers power to a clinic in Sierra Leone. solution in many countries, from the United States to China and Vietnam - is too expensive for rural regions with low population density and limited demand. The IEA says that $60 \%$ of new connections will need to come from decentralized minigrids and off-grid installations, such as solar home systems.

\section{BETTER TECHNOLOGIES}

Rapid improvements in low-carbon energy technologies have made 'green growth' an attractive development path for emerging economies, without ruinous increases in carbon emissions. The 791 million people in sub-Saharan Africa (excluding South Africa) consume only as much residential power as the 19.5 million people of $\mathrm{New}$ York State ${ }^{4}$. Even with today's conventional energy mix, universal access to modest amounts of electricity and clean-burning stoves by 2030 would add less than $1 \%$ to global energy-related emissions ${ }^{1}$.

In the past few years, clean-energy alternatives have become practical and affordable in many places - often cheaper than the dirty and dangerous fuels currently in use. The market for such products exists: an estimated $\$ 37$ billion is spent each year on kerosene for lighting and conventional cooking fuels such as charcoal - not far from the $\$ 48$ billion a year thought to be required to achieve universal access to modern energy services.

Where financing opportunities exist, a new breed of clean-energy entrepreneurs is emerging. SunFarmer, for example, is a US non-profit company that equips remote health clinics in Nepal with solar-electricity systems; Solar Sister is an enterprise that distributes solar products and clean cooking stoves through a network of female entrepreneurs mostly based in Uganda. These and other programmes that deliver electricity through microgrids and decentralized solutions are supported by the Energy Access Practitioner Network, a UN Foundation-led initiative launched in 2011 that shares knowledge among its 1,600 members in 191 countries.

The Global Alliance for Clean Cookstoves, also led by the UN Foundation, aims to create a global market for clean and efficient household stoves, with the goal of reaching 100 million households by 2020. The alliance is working with nearly 1,000 public, non-profit and private partners to drive investment, support entrepreneurs, conduct research and enhance testing of clean stoves in dozens of countries.

Three lessons from the rapid spread of wireless phones around the world (now used by nearly two-thirds of people in Africa) in the past 20 years also apply to energy. First, people at the bottom of the socio-economic pyramid can afford a technology if it has 


\section{POWER UP}

The benefits of existing policies for energy
access will be largely offset by population access will be largely offset by popula
growth, especially in Asia and Africa.
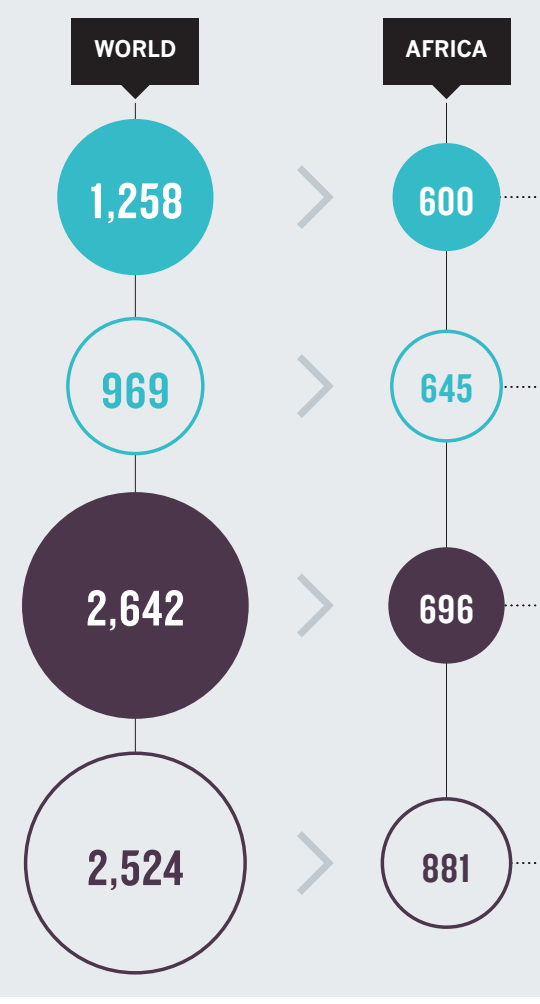

value to them and if appropriate financial terms are available, such as a pre-paid phone service that charges by the second rather than the minute. Second, leaping straight to more advanced technologies rather than extending conventional infrastructure means that customers can be reached more quickly and cost-effectively. Third, technology enables other economic benefits, such as market information that helps farmers to get a fair price for their crops.

Phones need electricity to recharge their batteries, so wireless-phone companies are exploring ways to provide power to rural areas. Strive Masiyiwa, the pioneering founder of telecommunications company Econet Wireless in Johannesburg, South Africa, created a subsidiary, Econet Solar, which offers products from low-voltage lighting to solar-powered televisions and radios. Phone and energy technologies promote new avenues for income generation. For example, solar lights can support a small mobile-phone charging business. Solar-powered water pumps enable irrigation and increase crop yields.

\section{ACCELERATE DEPLOYMENT}

More than 80 countries have committed to work with the Sustainable Energy for All initiative. Good intentions must now turn into real progress on the ground.
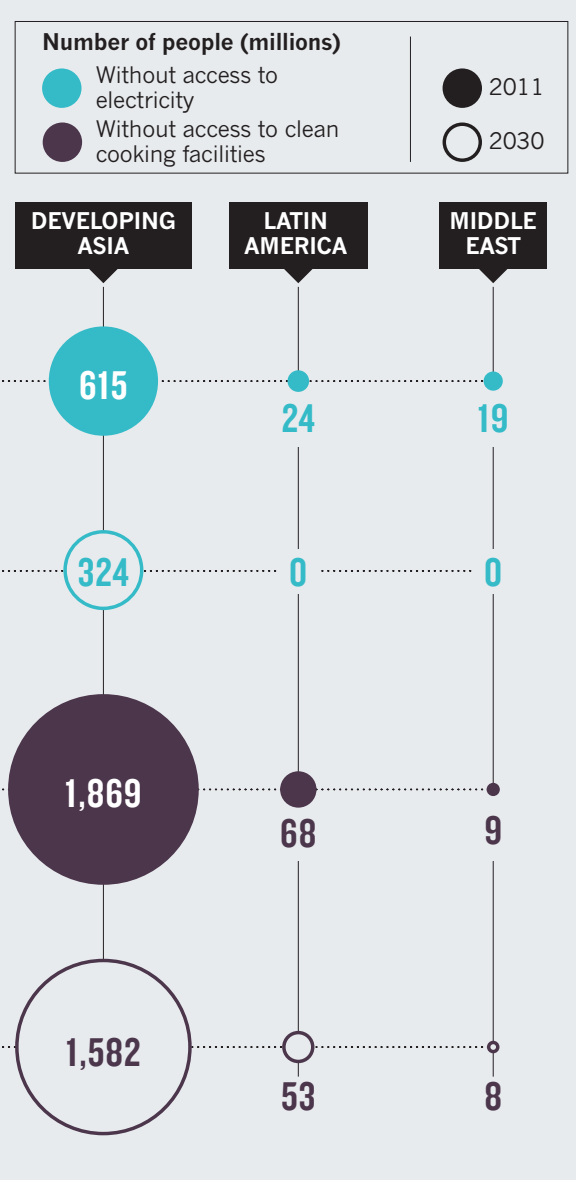

Government subsidies for charcoal and kerosene make it harder for cleaner technologies to penetrate the market; they should be phased out or repurposed to support clean-energy solutions, and targeted to the poorest. Tariffs on imported goods for energy access should be reduced or removed. More than 30 countries, including Kenya, Sierra Leone, Nigeria and Malawi, impose duties of $20-30 \%$ on solar lanterns and clean stoves to protect domestic indus -

$\begin{array}{ll}\text { "Tariffs on } & \text { try and raise rev- } \\ \text { imported goods } & \text { enues. Such tariffs } \\ \text { for energy } & \text { can take product } \\ \text { access should } & \text { prices beyond the } \\ \text { bereduced or } & \text { reach of the poor- } \\ \text { removed." } & \text { est consumers. } \\ & \text { To avoid the sale }\end{array}$
of poor-quality goods, governments should mandate compliance with global product standards established by international standard-setting bodies, such as the International Electrotechnical Commission and the International Finance Corporation's Lighting Global initiative. Energy service companies and practitioners should build local maintenance and service capacity, which is often neglected, into their projects to ensure that the systems do not fail prematurely.

Innovative financing is needed to overcome the high capital cost of installing renewable-energy systems. Investments in energy-access projects and products must be coupled with assistance in managing a growing business. Local banks must become more familiar with energy technologies and with lending to small and medium-size enterprises, including working capital to support expansion. The Global Alliance for Clean Cookstoves has launched several specialized funds to help entrepreneurs to grow in the sector, including a working capital facility with Deutsche Bank.

Techniques for channelling large-scale finance to multiple small-scale projects are needed. 'Green bonds', such as those issued by the International Finance Corporation, offer a low-risk investment proposition to finance clean energy and low-carbon projects and thus bundle and securitize debt. Partial loan guarantees have also been used to support energy projects. For example, the African Development Bank provided a partial guarantee for a wind-power project in Kenya to protect against political risks of delay or default.

UN discussions on development and climate change - now separate - should jointly embrace the three objectives of Sustainable Energy for All. Targets for eliminating energy poverty while doubling efficiency and renewables globally should be included in the Sustainable Development Goals to be adopted in 2015, now being debated at the UN General Assembly.

The next big event in climate negotiations is the UN climate summit in Paris in December 2015. Global agreement on the objectives of Sustainable Energy for All should be reached ahead of the meeting. That would fit squarely in the current 'bottom-up' narrative, in which individual countries are committing to concrete actions that reduce their emissions, rather than seeking a binding 'top-down' approach.

Sharing these powerful objectives, which Ban Ki-moon set several years ago, can link climate change and development goals and attract broad international support for both.

\section{Reid Detchon is vice-president for} energy and climate at the United Nations Foundation in Washington DC, USA. Richenda Van Leeuwen is executive director of energy access at the United Nations Foundation in Washington DC, USA. e-mail:rdetchon@unfoundation.org

1. International Energy Agency. World Energy Outlook 2013 (IEA, 2013).

2. World Health Organization. Burden of Disease from Household Air Pollution for 2012 (WHO, 2014).

3. Adair-Rohani, H. et al. Glob. Health Sci. Pract. 1, 249-261 (2013).

4. International Energy Agency. World Energy Outlook 2010 (IEA, 2010). 